\title{
Grain boundary control for improved intergranular stress corrosion cracking resistance in austenitic stainless steels: new approach
}

Link to publication record in Manchester Research Explorer

Citation for published version (APA):

Marrow, T. J., Engelberg, D., Jivkov, A., Wood, P., Babout, L., \& Stevens, N. (2006). Grain boundary control for improved intergranular stress corrosion cracking resistance in austenitic stainless steels: new approach. In Proceedings of Materials Congress 2006

Published in:

Proceedings of Materials Congress 2006

\section{Citing this paper}

Please note that where the full-text provided on Manchester Research Explorer is the Author Accepted Manuscript or Proof version this may differ from the final Published version. If citing, it is advised that you check and use the publisher's definitive version.

\section{General rights}

Copyright and moral rights for the publications made accessible in the Research Explorer are retained by the authors and/or other copyright owners and it is a condition of accessing publications that users recognise and abide by the legal requirements associated with these rights.

\section{Takedown policy}

If you believe that this document breaches copyright please refer to the University of Manchester's Takedown Procedures [http://man.ac.uk/04Y6Bo] or contact uml.scholarlycommunications@manchester.ac.uk providing relevant details, so we can investigate your claim.

\section{OPEN ACCESS}




\title{
Grain Boundary Control for Improved Intergranular Stress Corrosion Cracking Resistance in Austenitic Stainless Steels
}

\author{
J MARROW, D ENGELBERG, A JIVKOV, P WOOD, L. BABOUT, N STEVENS \\ Materials Performance Centre, University of Manchester, Oxford Rd, Manchester, UK \\ Tel.+44-161-306-3611, Fax. +44-161-306-3586, E-mail: james.marrow@manchester.ac.uk
}

\begin{abstract}
Grain boundaries of special character have resistance to corrosion and intergranular stress corrosion. The character can be described using geometrical schemes such as the coincidence site lattice (CSL) model, in which boundaries with low CSL index $(\Sigma)$ have lower energy and increased resistance. It has long been recognised that increasing the fraction of such boundaries will increase the resistance of a material to intergranular degradation.
\end{abstract}

This paper describes work which has focussed on the behaviour of special grain boundaries in sensitised austenitic stainless steel. The aim of the work was to develop a general model for stress corrosion cracking, which would ultimately be capable of predicting the effects of the degree of sensitisation, the connectivity of special boundaries and the influence of stress gradients, such as those developed from surface preparation (machining or peening) or due to the stress concentration effect of pit formation.

Experimental work using electron backscatter diffraction (EBSD) analysis and in-situ high-resolution computed X-ray tomography has correlated cracking with the microstructure in a Type 304 austenitic stainless steel. In-situ 3D observations demonstrated that annealing twins cause local crack arrest and diversion, leaving non-fractured ligaments in the wake of the cracking path. The mechanical effects of the deformation and failure of these bridges have been modelled, demonstrating that special grain boundaries cause crack tip shielding. Increasing the fraction of special boundaries, and decreasing grain size, are both predicted to increase stress corrosion cracking resistance. Experimental observations, using room temperature intergranular stress corrosion tests and high temperature autoclave tests confirm these predictions for thermo-mechanically processes microstructures. The effects of applied stress and stress gradients are also predicted by the model, which may be extended to include the kinetics of crack growth, clustering of grain boundary types and variation of the degree of sensitisation.

KEYWORDS :Stress Corrosion Cracking, Austenitic Stainless Steels, Tomography, Grain Boundary Engineering, Modelling.

\section{INTRODUCTION}

Stress corrosion cracking is a significant potential cause of failures in the nuclear power industry [1]. Cracking frequently nucleates from corrosion pits [2] and, depending on the material and environment, may be transgranular or intergranular in nature. The incubation period depends on factors including the rate of pit/localized corrosion formation and growth, the transition from pit/localized corrosion to crack initiation, and the propagation of short cracks with a size comparable to the microstructure scale. Although models for these processes have been developed [e.g. 3], the prediction of incubation periods remains uncertain due to the complex interaction between microstructure, environment and the mechanisms of localized corrosion and environmentally assisted cracking.

This paper reports an on-going research programme into the mechanisms of intergranular stress corrosion cracking in austenitic stainless steels in simulated light water environments. These make use of new analytical and modelling techniques to develop an improved mechanistic understanding of the influence of materials, environment and stress on SCC. The work aims to establish new approaches for the engineering of microstructures and surfaces to develop stainless steels with improved SCC resistance. 
Recent results, which are described in this paper include

- Analysis of the distributions of grain boundary character and grain boundary triple junctions have been combined with the new mechanistic understanding of IGSCC to develop trend models for the effects of grain boundary engineering on crack propagation resistance.

- In-situ, high resolution X-ray tomographic observations of intergranular stress corrosion crack nucleation and growth in sensitised austenitic stainless steel.

- Two-dimensional and three-dimensional intergranular crack propagation models for short stress corrosion crack development and interactions.

\section{STRESS CORROSION CRACKING RESEARCH}

\section{Microstructure Characterisation}

"Grain Boundary Design and Control" [4] aims to develop specific material properties, in particular the intergranular corrosion (IGC) and intergranular stress corrosion cracking (IGSCC) resistance. The approach characterises the grain boundary network as a heterogeneous entity, based on the crystallographic relations of adjacent grains. Grain boundary (GB) design is typically applied to low and medium stacking fault energy face centred cubic (FCC) materials, and also known as Grain Boundary Engineering (GBE). This is commonly achieved by thermal and thermo-mechanical processing.

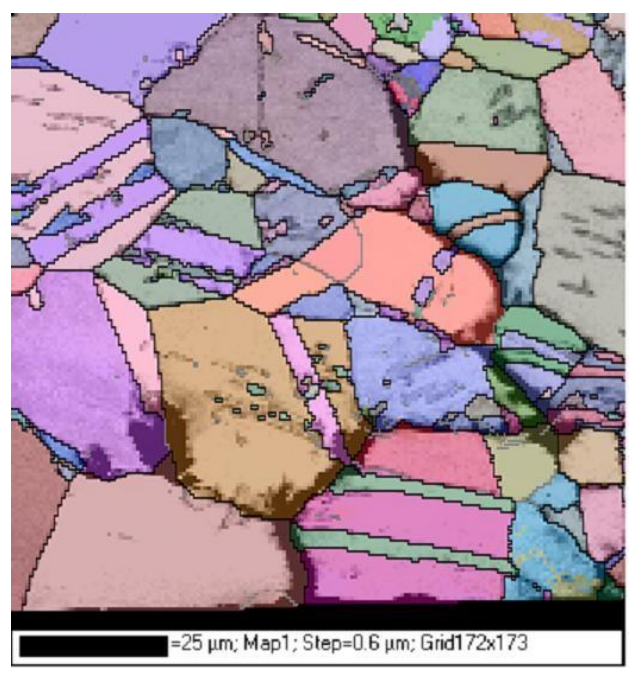

Figure 1: Electron backscatter map of intergranular cracking in sensitized 304 austenitic stainless steel. The surface, at which the crack nucleated, is to the bottom of the figure. The crack is black.

Electron Backscatter Diffraction (EBSD) techniques, interfaced to a Scanning Electron Microscope (SEM), are typically employed to assess statistically significant grain orientation populations [4]. Crystallographic as well as spatial information about the grain orientations is recorded. This data can then be used to determine a Grain Boundary Character Distribution (GBCD), which is representative of the microstructure. The GBCD is a discrete population of grain boundary types, based on either their frequencies or relative length fractions. EBSD may also be used to study the interaction of stress corrosion crack with microstructure (Figure 1).

A microstructure engineering study has been performed to investigate the effects of thermo-mechanical processing on the parameters likely to improve stress corrosion cracking resistance in sensitised type 304 austenitic stainless steel [6, 7]. The study was based on the proposition that the resistance to stress corrosion cracking develops from grain boundary triple junctions with a resistant grain boundary (i.e. a non-sensitised boundary). These are generally found to be boundaries with a high degree of coincidence between the crystal lattice orientations of the grains on either side of the boundary, defined using the coincidence site lattice (CSL) model. Twin boundaries ( $\Sigma 3)$ and some low CSL boundaries with $\Sigma \leq 29$ are commonly observed as resistant to intergranular corrosion and stress corrosion cracking, although this may vary with environment [6]. Crack propagation depends on the frequency with resistant triple junctions are encountered by the crack tip, thus both grain size and the grain boundary character distribution are significant parameters.

The effect of grain boundary engineering on the population of cracks developed in stressed specimens has been investigated [6]. The crack lengths have a log-normal population, and hence extreme value statistics, in the form of Gumbel distributions, were applied to evaluate the crack population. This method allows the crack population to be described by measuring the longest cracks in the sample, expressed as the reduced parameter, y. Typical results are given in Figure 2, which demonstrates the significant influence of microstructure on crack propagation. The 30\%/900/30 microstructure, which has the greater resistance, has a reduced grain size and lower fraction of twin and low CSL boundaries than the as-received microstructure. It was cold worked by $30 \%$ and annealed at $900^{\circ} \mathrm{C}$ for 30 minutes. Mechanistic models for the effects of microstructure modification have 
been developed, based on three-dimensional characterisation of cracking behaviour.

(a)
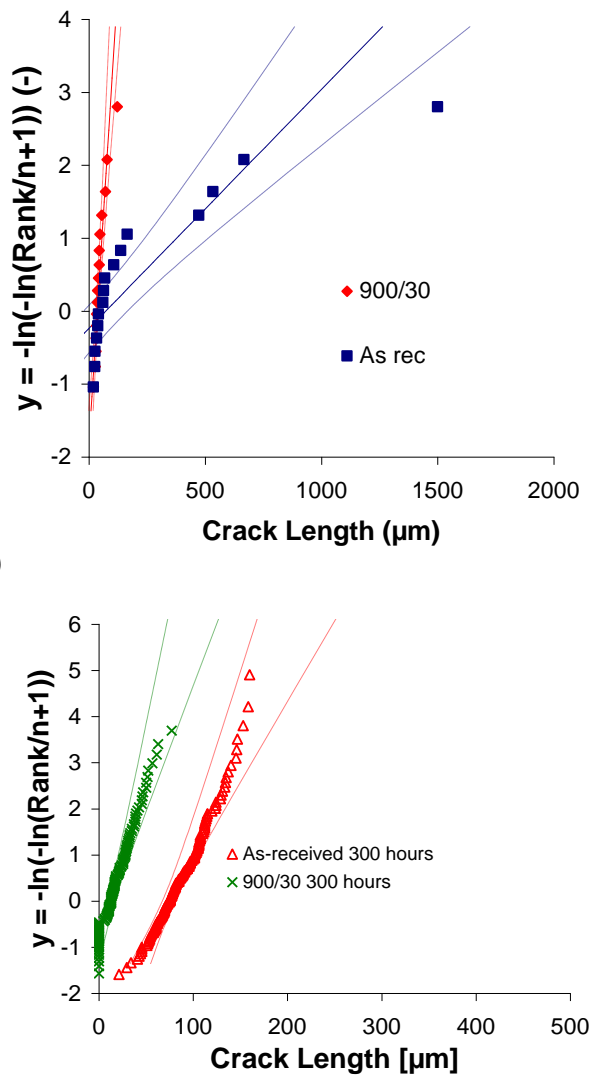

(b)

Figure 2: Crack population data (a) under an applied stress of $200 \mathrm{MPa}$ for 144 hours in pH $2.5 \mathrm{~K}_{2} \mathrm{~S}_{4} \mathrm{O}_{6}$ solution, (b) under an applied stress of $244 \mathrm{MPa}$ in $0.01 \mathrm{M} \mathrm{Na} \mathrm{SO}_{4}$ electrolyte at $523 \mathrm{~K}\left(250{ }^{\circ} \mathrm{C}\right)$ and a pressure of 40 bar for 300 hours. Solid lines are least square best fits to the data. Dashed lines are the $95 \%$ confidence limits.

\section{Three Dimensional Characterisation}

The interaction between a propagating intergranular stress corrosion crack and the microstructure has been investigated by in-situ three dimensional observations of intergranular stress corrosion cracking, using the ID19 X-ray microtomography beam line at the European Synchrotron Radiation Facility (ESRF), France [7-9]. An annealed and fully sensitised 302 stainless steel wire (400 $\mu$ m diameter) was tested in $0.15 \mathrm{M}$ potassium tetrathionate $\left(\mathrm{K}_{2} \mathrm{~S}_{4} \mathrm{O}_{6}\right)(\mathrm{pH} 2)$.

The progressive failure of the bridging ligaments was observed at the different stages of the experiment (Figure 3). These tomographic observations enable three-dimensional visualization of the stress corrosion crack (e.g. Figure 4). Correlation of the location of the crack bridging ligaments with fractographic observations at the same locations, confirms that the ligaments are associated with ductile features, which have a morphology consistent with their formation by annealing twin growth (Figure 5).

These observations imply that non-sensitised special boundaries are resistant to stress corrosion cracking, and the crack propagates around the obstacle formed by these ligaments. The ductile failure of the ligaments is expected to shield the crack tip from the applied stress. Consequently, grain boundary engineering to increase the number and size of such ligaments may be expected to improve stress corrosion cracking resistance.

\section{Modelling of Stress Corrosion Cracking}

Two-dimensional [7, 10] analytical and finite element models, and three-dimensional [11] finite element models for intergranular crack propagation, which quantify the effect of crack bridging ligaments on short crack development, have been developed. These models have been used to assess the effects of crack bridging and crack branching for a range of fractions of susceptible boundaries. The models, which assume a critical crack tip strain for crack propagation, show that both the fraction of susceptible boundaries and the ductile ligament failure strain control the shielding effect of bridges. Typical data, obtained by Monte-Carlo methods for randomized distributions of resistant boundaries using the 2D finite element model, is shown in Figure 6. The effects of surface residual stresses can be modelled and typical results are given in Figure 7 . The model predicts crack retardation and arrest, which is observed in experiments. The three-dimensional model has also been applied to study the interaction and coalescence of stress corrosion cracks. Typical data is given in Figure 8, and is consistent with the real behaviour of stress corrosion cracks.

The modeling methodology developed therefore appears to satisfactorily reproduce the observed effects of microstructure and 
residual stress on stress corrosion crack behaviour. Further work is in progress to validate the model against a range of thermo-mechanically processed microstructures, with varying surface residual stress state. The model does not currently address the kinetic aspects of stress corrosion crack propagation, for which a detailed understanding of crack tip processes is required. Work is also in progress to investigate the significance of clustering of boundaries of similar character.

a)
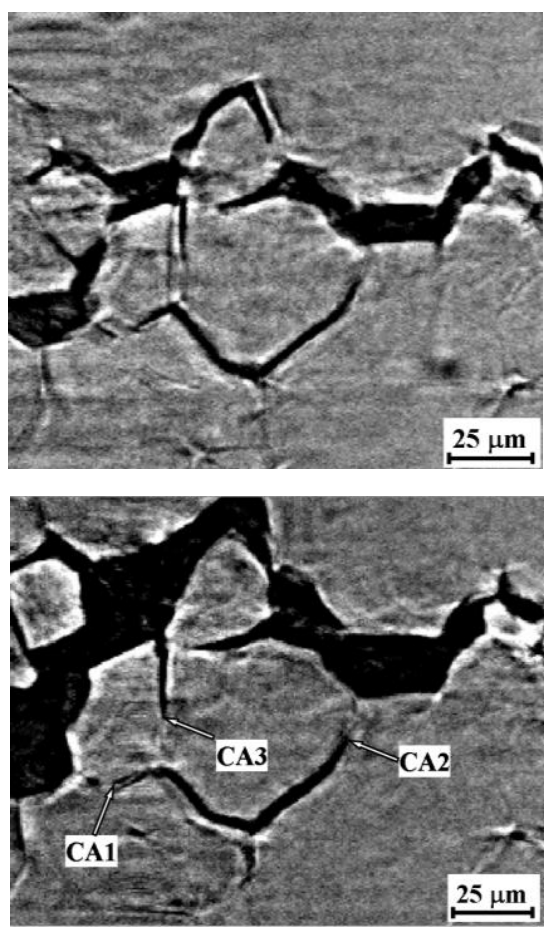

Figure 3: Tomographic data obtained as successive periods (a and b) during stress corrosion cracking. Progressive failure of crack bridging ligaments is observed. CA1, and CA2 are indicated in Figure 4

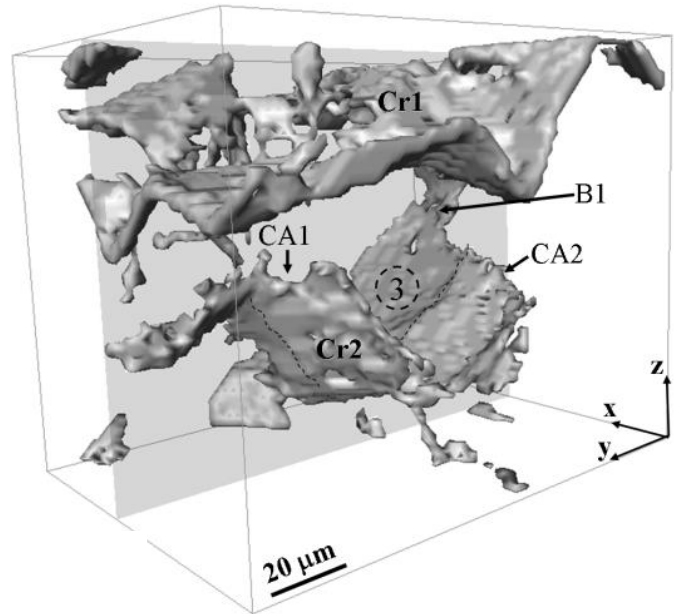

Figure 4: Three dimensional reconstruction of part of a stress corrosion crack. Features CA1 ands CA2 are identified in Figure 3. Cr1, Cr2 and 3 are separate regions of cracking, joined by B1.

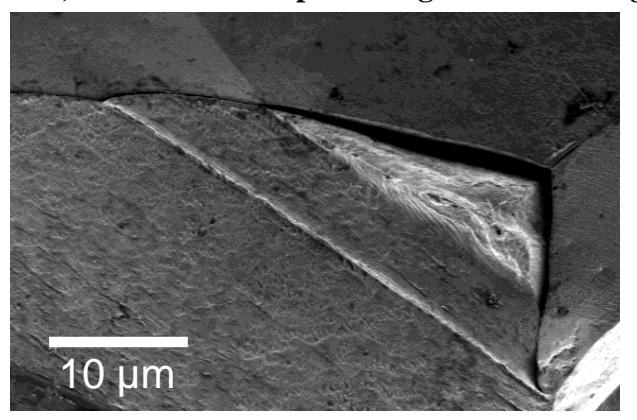

Figure 5: Ductile failure of a crack bridging ligament. 


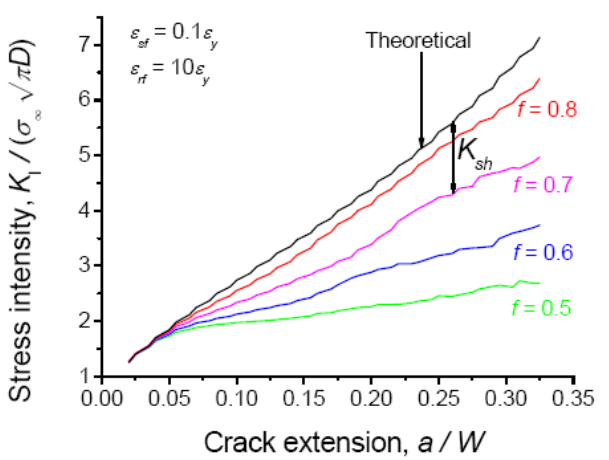

Figure 6: Two dimensional model for the development of the crack tip stress intensity factor $(K)$ with applied stress $\left(\sigma_{\infty}\right)$ for a microstructure with grain size (D) as the crack length (a) increases $(W=50 D)$. The theoretical stress intensity factor for an unbridged crack is compared against the effects of different fractions (f) of susceptible grain boundaries. The failure strain of susceptible boundaries is $1 \%$ of the failure strain of resistant boundaries.

a)
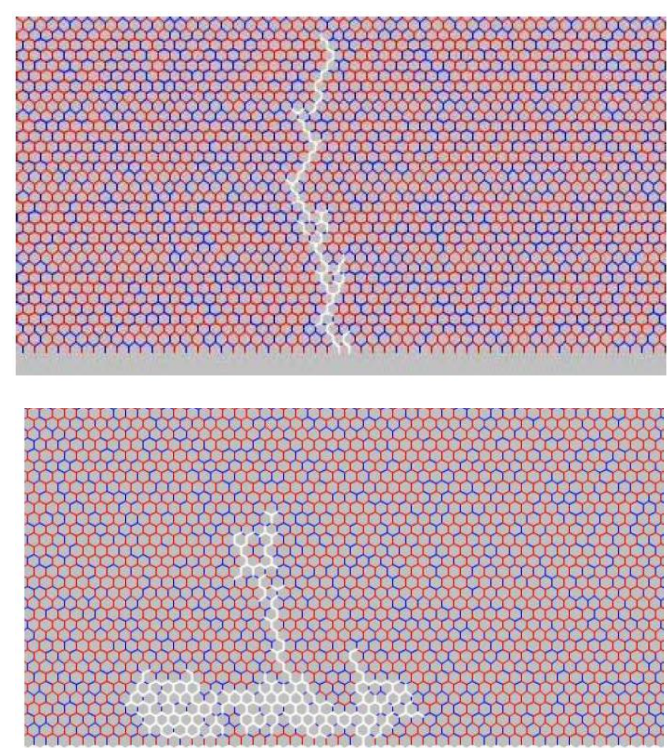

Figure 7: Typical results for the development of cracks using the 2D model with crack bridge development for a) applied tensile stress, b) applied tensile stress with sub-surface compressive residual stress. 


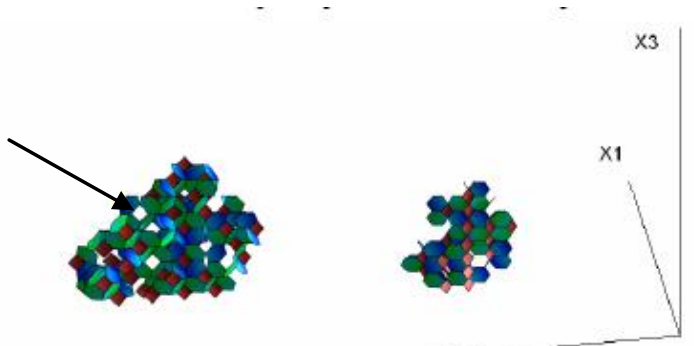

$x_{2}$

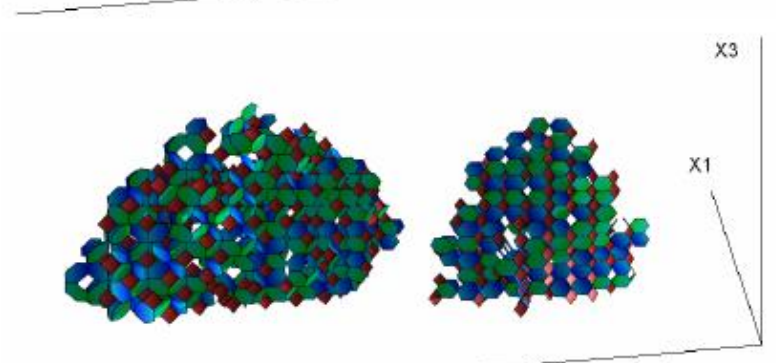

$\times 2$

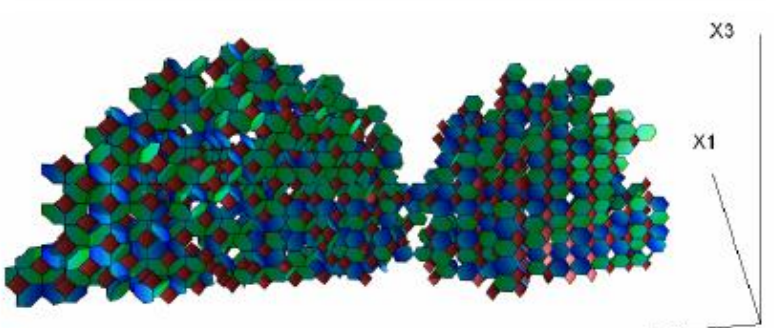

$\times 2$

Figure 8: Three-dimensional model for the growth and coalescence of intergranular stress corrosion cracks. Crack bridging (open spaces) is indicated by an arrow.

\section{CONCLUSIONS}

The propagation of short intergranular stress corrosion cracks is influenced by microstructure and residual stress. Two and three-dimensional models for crack behaviour have been developed, guided by high resolution observations of the mechanism of crack propagation. These models are being validated using test specimens with well characterized microstructures and surface residual stress distributions.

\section{ACKNOWLEDGMENTS}

The authors are grateful to EPSRC, Rolls Royce Plc and Serco Assurance for their independent support of the research described in this paper. The views expressed are those of the authors and not necessarily those of the research sponsors.

\section{REFERENCES}

1. P.M. Scott., Stress corrosion cracking in pressurized water reactors - Interpretation, modeling, and remedies, Corrosion, 56, (2000), 771-782.

2. R.C. Newman, Understanding the corrosion of stainless steel, Corrosion, 57, (2001), 1030-1041.

3. T.K. Christman, Relationships between pitting, stress, and stress-corrosion cracking of line pipe steels, Corrosion, 46, (1990), 450-453.

4. T. Watanabe, An approach to grain-boundary design for strong and ductile polycrystals, Res. Mechanica, (1984), 47.

5. F.J. Humphreys, Review - Grain and subgrain characterisation by electron backscatter diffraction, Journal of Materials Science, (2001), 36, 3833.

6. D.L. Engelberg, T.J. Marrow, L. Babout and R.C. Newman, Grain Boundary Engineering for Crack Bridging: Intergranular Corrosion and Stress Corrosion Crack Path Dependencies, $16^{\text {th }}$ International Corrosion Conference, (2005), Beijing, China.

7. D.L.Engelberg, T.J.Marrow, R.C.Newman, L.Babout, A new model for IGSCC propagation, Second International Conference on Environment- Induced Cracking of Metals, EICM-2, (2004), Banff, Canada 
8. T.J. Marrow, L. Babout, A.P. Jivkov, P. Wood, D. Engelberg, N. Stevens, P.J. Withers, Three dimensional observations and modelling of intergranular stress corrosion cracking in austenitic stainless steel, E-MRS Spring Meeting, Strasbourg, France, (2005). In press, Journal of Nuclear Materials (2006).

9. L. Babout, T.J. Marrow, D. Engelberg, P.J. Withers, X-ray microtomographic observation of intergranular stress corrosion cracking in sensitised austenitic stainless steel, In press, Materials Science and Technology (2006).

10. A.P. Jivkov, N.P.C. Stevens and T.J. Marrow, A 2D mesoscale model for intergranular stress corrosion crack propagation, In press, Acta Materialia (2006).

11. A. P. Jivkov, N. P. C. Stevens and T. J. Marrow, A three-dimensional computational model for intergranular cracking, In press, Computational Materials Science (2006). 